\title{
MORPHOMETRY AND SEXUAL DIMORPHISM OF LUMBAR PEDICLES IN DRY BONES OF MAHARASHTRA REGION
}

\author{
Yallawa S Kamble ${ }^{* 1}$, Pramod R. Kulkarni ${ }^{2}$, Uttama U Joshi ${ }^{3}$.
}

${ }^{*}$ Tutor in anatomy Bharati Vidyapeeth Deemed University Medical College and Hospital Sangli, Maharashtra, India.

${ }^{2}$ Professor and Head Department of Anatomy, Dr. V. M. Government Medical College, Solapur. Maharashtra, India.

${ }^{3}$ Associate Professor, Department of Anatomy, Bharati Vidyapeeth Deemed University Medical College and Hospital Sangli, Maharashtra, India.

\section{ABSTRACT}

Introduction: Pedicle is strongest part of lumbar vertebra. The fixation of lumbar spine is needed for various spinal problems. The transpedicular screw fixation of lumbar spine is developed as a very successful method of spinal fixation. Morphometric data on the parameters of the pedicles is therefore useful in preoperative planning and designing of pedicle screws and other implantable devices. Identification of sex of an individual from the remains of skeleton has great medico legal significance.

Aims and Objectives: To measure the height, thickness and length of lumbar pedicles in dry bones and find out sexual dimorphism in Maharashtra region.

Materials and Method: 70 sets of known sex ( 35 male and 35 female) of lumbar vertebrae from L1 to L5 were obtained from Department of Anatomy of various Medical Colleges of Maharashtra region. The height, thickness and length of lumbar pedicles were measured by using digital vernier caliper. The data was statistically evaluated and seen for sexual dimorphism.

Observations and Results: The height and length of pedicle increased from L1 to L3 and decreased up to L5 levels on right and left side in both sexes. The thickness of pedicle increased from L1 to L5 levels on both right and left side and in both sexes. Height (right side L1 to L4 and on left side at all vertebral levels) and thickness of lumbar pedicle ( $L 1$ to $L 3$ on right side and $L 1, L 2, L 3$ and $L 5$ on left side) exhibited sexual dimorphic features in lumbar vertebrae. However, statistically significant difference was not observed in the length of pedicle.

Conclusion: The present study confirmed that there are regional as well as racial variations in the parameters of lumbar pedicles. This necessitates the study of particular geographic area and population to find out the range of normal values for that particular population and thus can be helpful for instrumentation. Height $\&$ thickness of pedicle showed sexual dimorphic features particularly in L1 to L3 levels, which can be considered for sex determination. Present study can be useful in designing pedicle screw and also be helpful for anthropometric studies and forensic investigations.

KEY WORDS: Lumbar pedicle, Screw fixation, Sexual dimorphism, Maharashtra region.

Address for Correspondence: Ms. Yallawa S. Kamble, Department of Anatomy, Bharati Vidyapeeth Deemed University Medical College and Hospital Sangli, 416416, Maharashtra, India.

Contact Number: +919604832758 E-Mail:yogitakamble684@gmail.com

\begin{tabular}{|c|c|c|}
\hline \multicolumn{3}{|c|}{ Access this Article online } \\
\hline \multirow{2}{*}{$\begin{array}{l}\text { Quick Response code } \\
\text { DOI: } 10.16965 / \text { ijar.2017.428 }\end{array}$} & \multicolumn{2}{|c|}{$\begin{array}{l}\text { Web site: International Journal of Anatomy and Research } \\
\qquad \text { ISSN 2321-4287 } \\
\text { www.ijmhr.org/ijar.htm }\end{array}$} \\
\hline & $\begin{array}{l}\text { Received: } 23 \text { Aug } 2017 \\
\text { Peer Review: } 23 \text { Aug } 2017 \\
\text { Revised: } 28 \text { Aug } 2017\end{array}$ & $\begin{array}{l}\text { Accepted: } 20 \text { Oct } 2017 \\
\text { Published (O): } 01 \text { Dec } 2017 \\
\text { Published (P): } 01 \text { Dec } 2017\end{array}$ \\
\hline
\end{tabular}




\section{INTRODUCTION}

The lumbar vertebrae are identified by, their large size, absence of costal facets on the body and absence of foramen transversarium. The spine is short and rounded at the tip.

There are five lumbar vertebrae. First four are typical and fifth is atypical. Atypical lumbar (Fifth) vertebra is identified by the distance between inferior articular processes, which is equal or more than the distance between superior articular processes. The transverse processes are thick, short and pyramidal in shape [1].

Pedicle is the strongest part of lumbar vertebra. It acts as strut to transmit forces between body and neural arch. It is highly loaded element of neural arch along with facets and laminae. The pedicles of lumbar vertebrae are close to the horizontal position hence the weight transmission in lumbar spine is from body to neural arch towards line of gravity and they connect anterior column (body) to posterior column (neural arch) [2].

The lumbar region of vertebral column is frequently involved during accidents, degenerative conditions, congenital defects and neoplastic metastases. Thus it requires instrumentation for its anatomy and activity to be regained. Surgical intervention in this region requires a thorough knowledge of anatomy and different parameters of pedicles of lumbar vertebrae to identify suitable sites for instrumentation and spinal fixation $[3,4]$.

The choice of screw is determined by minimum horizontal diameter of pedicle whereas the pathway of the screw is decided by transverse and vertical parameters of the pedicle [5-7]. Morphometric data on the diameters of the pedicles are therefore useful in preoperative planning. The details of pedicle morphometry become important not only in designing of pedicle screw but also in selection of suited pedicle screw and other implantable devices.

Morphometric measurements of skeleton also provide important and useful data regarding the race to which they belong. This helps to determine the age, sex, and stature of an individual. Identification of sex of an individual from the remains of skeleton has great medico legal significance. Sexual dimorphism in vertebrae has received little attention and has been also used as basis for sex prediction in the analysis of skeletal materials (particularly when bones like hip, skull, sacrum etc are not available). The present study was undertaken in Maharashtra region to measure the height, thickness and length of lumbar pedicles in both sexes. Thus this study was an attempt to collect the database for detailed knowledge of different parameters of pedicles of lumbar vertebrae in dry bones.

AIM: To study morphometry and sexual dimorphism of lumbar pedicles in dry bones of Maharashtra region.

OBJECTIVES: To measure the height, thickness and length of pedicles of lumbar vertebrae in Maharashtra region. To evaluate the data for sexual difference in height, thickness and length of pedicles of lumbar vertebrae.

\section{MATERIALS AND METHODS}

\section{Study Design: Cross sectional study}

Sample Size: 70 sets of known sex (35 male and 35 female) of lumbar vertebrae obtained from Department of Anatomy of various Medical Collages of Maharashtra.

Inclusion Criteria: Normal and fully ossified lumbar vertebrae

Exclusion Criteria: Deformed And broken vertebrae

Method: After obtaining ethical approval, 70 sets ( 35 male and 35 female) of lumbar vertebrae from L1 to $L 5$ were obtained from Department of Anatomy of various Medical Collages of Maharashtra region. Following measurements were recorded on both sides using a digital vernier caliper (Precision 0.01 $\mathrm{mm}$ ). Three readings were taken for each measurements and mean of these was obtained to exclude the personal error. All measurements were recorded in $\mathrm{mm}$.

Height: This was measured as maximum vertical distance at the posterior end of pedicle between superior and inferior border of pedicle.

After obtaining the measurements, readings were tabulated and analyzed. The range of measurements of parameters (minimum and maximum values) and standard deviation were calculated. The parameters in males and 
females were compared with each other to know sexual dimorphism by applying ' $Z$ ' test. For each of the parameter, ' $p$ ' values were calculated. It was interpreted as $-p<0.01$ was considered as highly significant, $p<0.05$ significant and $p>0.05$ not significant. Statistical calculations were done with help of Statistical Software (SPSS Software version 22).

Fig. 1: Height of the Pedicle.

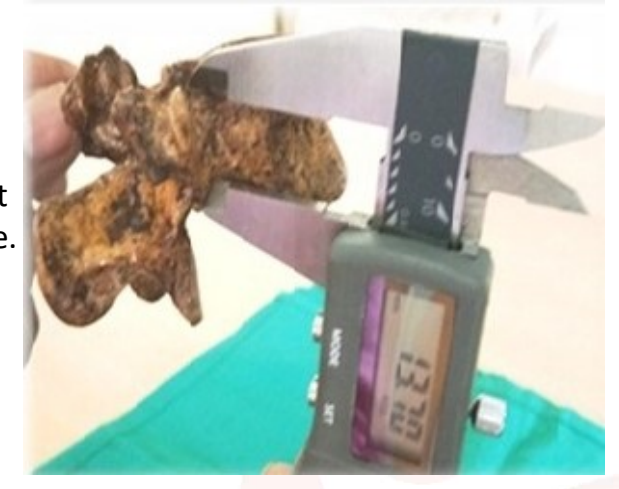

Thickness: This was measured as a distance between medial and lateral surface at the posterior end of pedicle.

Fig. 2:

Thickness of the Pedicle.

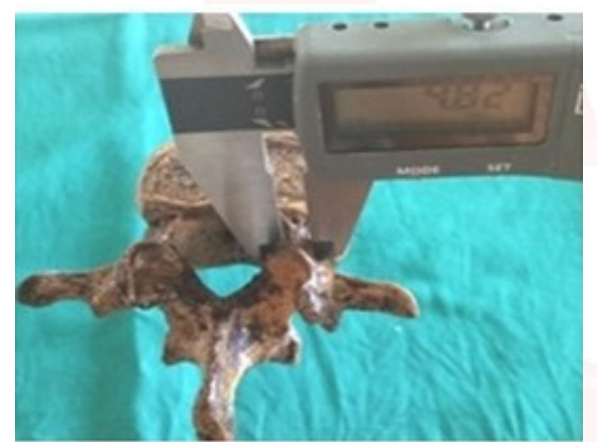

Length: This was measured distance between two points, one at the junction of pedicle and vertebral body and second at junction of pedicle and superior articular process.

Fig. 3: Length of the Pedicle.

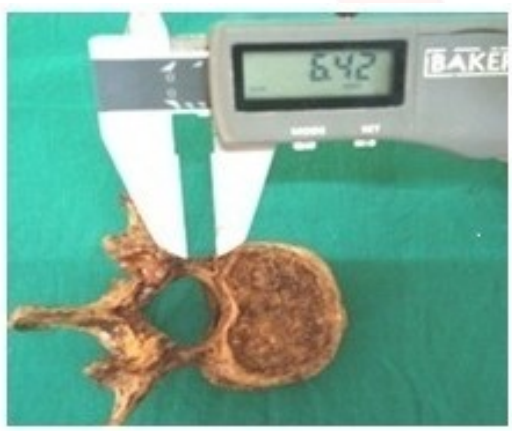

Photograph 3 Length of Pedicle

\section{OBSERVATIONS AND RESULTS}

The height of right sided pedicle increased from $L 1$ to $L 3$ level and decreased at L4 and L5 levels in both sexes. The mean height of right sided pedicle was maximum at $L 3$ level and minimum at $L 5$ level in both the sexes. The difference between the mean values of male and female vertebrae was statically significant at all vertebral levels except at $L 5$.

Table 1: Height $(\mathrm{mm})$ of right side pedicle in male and female vertebrae.

\begin{tabular}{|c|c|c|c|c|c|c|}
\hline Vertebra & Sex & Mean & S.D. & Range & p Value & Significance \\
\hline \multirow{2}{*}{ L1 } & $\mathrm{M}$ & 13.98 & 1.24 & $11-17$ & \multirow{2}{*}{0.001} & \multirow{2}{*}{ HS } \\
\cline { 2 - 5 } & $\mathrm{F}$ & 13.07 & 0.91 & $11-15$ & & \\
\hline \multirow{2}{*}{ L2 } & $\mathrm{M}$ & 14.4 & 1.16 & $12-18$ & \multirow{2}{*}{0.01} & \multirow{2}{*}{$\mathrm{S}$} \\
\cline { 2 - 5 } & $\mathrm{F}$ & 13.72 & 0.97 & $12-16$ & & \\
\hline \multirow{2}{*}{ L3 } & $\mathrm{M}$ & 15.23 & 1.14 & $13-18$ & \multirow{2}{*}{$\mathbf{0 . 0 0 1}$} & \multirow{2}{*}{ HS } \\
\cline { 2 - 5 } & $\mathrm{F}$ & 14.26 & 1.22 & $12-17$ & & \\
\hline \multirow{2}{*}{ L4 } & $\mathrm{M}$ & 13.11 & 1.16 & $10-15$ & \multirow{2}{*}{$\mathbf{0 . 0 0 2}$} & \multirow{2}{*}{ HS } \\
\cline { 2 - 5 } & $\mathrm{F}$ & 12.16 & 1.24 & $10-15$ & & \\
\hline \multirow{2}{*}{ L5 } & $\mathrm{M}$ & 11 & 1.73 & $6-14$ & \multirow{2}{*}{0.269} & \multirow{2}{*}{ NS } \\
\cline { 2 - 5 } & $\mathrm{F}$ & 10.59 & 1.31 & $8-17$ & & \multicolumn{2}{|c}{} \\
\hline
\end{tabular}

Table 2: Height $(\mathrm{mm})$ of left side pedicle in male and female vertebrae.

\begin{tabular}{|c|c|c|c|c|c|c|}
\hline Vertebra & Sex & Mean & S.D. & Range & $p$ Value & Significance \\
\hline \multirow{2}{*}{ L1 } & M & 13.8 & 1.04 & $12-16$ & \multirow{2}{*}{0.001} & \multirow{2}{*}{ HS } \\
\hline & $\mathrm{F}$ & 12.91 & 1.06 & $11-15$ & & \\
\hline \multirow{2}{*}{ L2 } & M & 14.15 & 0.99 & $12-16$ & \multirow{2}{*}{0.002} & \multirow{2}{*}{ HS } \\
\hline & $\mathrm{F}$ & 13.39 & 1.06 & $11-15$ & & \\
\hline \multirow{2}{*}{ L3 } & M & 14.85 & 1.23 & $13-19$ & \multirow{2}{*}{0.012} & \multirow{2}{*}{ S } \\
\hline & $\mathrm{F}$ & 14.11 & 1.17 & $11-16$ & & \\
\hline \multirow{2}{*}{ L4 } & M & 12.78 & 1.13 & $10-16$ & \multirow{2}{*}{0.002} & \multirow{2}{*}{ HS } \\
\hline & $\mathrm{F}$ & 12.02 & 0.87 & $10-14$ & & \\
\hline \multirow{2}{*}{ L5 } & M & 10.89 & 1.3 & $7-14$ & \multirow{2}{*}{0.03} & \multirow{2}{*}{ s } \\
\hline & $\mathrm{F}$ & 10.19 & 1.34 & $8-13$ & & \\
\hline
\end{tabular}

The height of left side pedicle increased from $L 1$ to $L 3$ level with maximum height at L3. The height then decreased at L4 and L5 in both sexes. The difference between mean values of male and female vertebrae was statistically highly significant at L1, L2 and L4 level and significant at L3 and L5 levels.

Table 3: Thickness $(\mathrm{mm})$ of right side pedicle in male and female vertebrae.

\begin{tabular}{|c|c|c|c|c|c|c|}
\hline Vertebra & Sex & Mean & S.D. & Range & $p$ Value & Significance \\
\hline \multirow{2}{*}{ L1 } & $M$ & 7.47 & 1.1 & 5-11 & \multirow{2}{*}{0} & \multirow{2}{*}{ HS } \\
\hline & $\mathrm{F}$ & 6.4 & 1.03 & $5-9$ & & \\
\hline \multirow{2}{*}{ L2 } & $M$ & 8.33 & 1.23 & $5-11$ & \multirow{2}{*}{0} & \multirow{2}{*}{ HS } \\
\hline & $\mathrm{F}$ & 7.19 & 1.14 & $6-10$ & & \\
\hline \multirow{2}{*}{ L3 } & $M$ & 9.51 & 1.59 & $6-12$ & \multirow{2}{*}{0.005} & \multirow{2}{*}{ HS } \\
\hline & $\bar{F}$ & 8.51 & 1.29 & $6-11$ & & \\
\hline \multirow{2}{*}{ L4 } & $M$ & 10.44 & 1.66 & $6-13$ & \multirow{2}{*}{0.312} & \multirow{2}{*}{ NS } \\
\hline & $\mathrm{F}$ & 10.02 & 1.71 & $6-13$ & & \\
\hline \multirow{2}{*}{ L5 } & $M$ & 13.65 & 2.35 & $9-18$ & \multirow{2}{*}{0.059} & \multirow{2}{*}{ NS } \\
\hline & $\mathrm{F}$ & 12.58 & 2.28 & $9-18$ & & \\
\hline
\end{tabular}

The thickness of right side pedicle increased from L1 to $L 5$ level in both sexes. The thickness of the pedicle was maximum at $L 5$ level and minimum at L1 level in both the sexes. The difference between the mean values of male 
and female vertebrae was statistically highly significant at L1, L2 and L3 levels whereas the difference was not significant at L4 and L5 vertebrae.

Table 4: Thickness $(\mathrm{mm})$ of left side pedicle in male and female vertebrae.

\begin{tabular}{|c|c|c|c|c|c|c|}
\hline Vertebra & Sex & Mean & S.D. & Range & p Value & Significance \\
\hline \multirow{2}{*}{ L1 } & $M$ & 7.51 & 1.52 & $5-10$ & \multirow{2}{*}{0.005} & \multirow{2}{*}{ HS } \\
\hline & $\mathrm{F}$ & 6.63 & 0.92 & $5-9$ & & \\
\hline \multirow{2}{*}{ L2 } & $M$ & 8.2 & 0.96 & $5-11$ & \multirow{2}{*}{0.001} & \multirow{2}{*}{ HS } \\
\hline & $\bar{F}$ & 7.39 & 0.97 & $5-9$ & & \\
\hline \multirow{2}{*}{ L3 } & $M$ & 9.41 & 1.18 & 6-12 & \multirow{2}{*}{0.002} & \multirow{2}{*}{ HS } \\
\hline & $F$ & 8.46 & 1.21 & $6-11$ & & \\
\hline \multirow{2}{*}{ L4 } & $M$ & 10.74 & 1.52 & $6-13$ & \multirow{2}{*}{0.146} & \multirow{2}{*}{ NS } \\
\hline & $\mathrm{F}$ & 10.21 & 1.5 & $7-13$ & & \\
\hline \multirow{2}{*}{ L5 } & $M$ & 13.98 & 2.29 & $9-18$ & \multirow{2}{*}{0.03} & \multirow{2}{*}{$S$} \\
\hline & $\bar{F}$ & 12.83 & 2.07 & $10-18$ & & \\
\hline
\end{tabular}

The thickness of left side pedicle increased from L1 to $L 5$ level in both sexes. The thickness of the pedicle was maximum at L5 level and minimum at L1 level in both the sexes. The difference between the mean values of male and female vertebrae was statistically highly significant at $L 1$ to $L 3$ level and significant at $L 5$ level but not significant at L4 level.

Table 5: Length $(\mathrm{mm})$ of right side pedicle in male and female vertebrae.

\begin{tabular}{|c|c|c|c|c|c|c|}
\hline Vertebra & Sex & Mean & S.D. & Range & p Value & Significance \\
\hline \multirow{2}{*}{ L1 } & M & 6.74 & 0.84 & $5-9$ & \multirow{2}{*}{0.643} & NS \\
\cline { 2 - 5 } & F & 6.84 & 0.97 & $5-9$ & & \\
\hline \multirow{2}{*}{ L2 } & M & 7.17 & 1.04 & $5-10$ & \multirow{2}{*}{0.394} & \multirow{2}{*}{ NS } \\
\cline { 2 - 5 } & F & 7.39 & 1.04 & $5-10$ & & \\
\hline \multirow{2}{*}{ L3 } & M & 7.91 & 1.4 & $6-11$ & \multirow{2}{*}{0.606} & \multirow{2}{*}{ NS } \\
\cline { 2 - 5 } & F & 8.07 & 1.12 & $6-13$ & & \\
\hline \multirow{2}{*}{ L4 } & M & 6.24 & 0.82 & $4-8$ & \multirow{2}{*}{0.857} & \multirow{2}{*}{ NS } \\
\cline { 2 - 5 } & F & 6.28 & 0.85 & $4-8$ & & \\
\hline \multirow{2}{*}{ L5 } & M & 5.49 & 0.84 & $4-7$ & \multirow{2}{*}{0.327} & NS \\
\cline { 2 - 5 } & F & 5.68 & 0.74 & $4-7$ & & \\
\hline
\end{tabular}

The length of right side pedicle increased from L1 to L3 and then decreased up to L5 level in both sexes. The difference between mean values in male and female was not significant at any level.

The length of left side pedicle increased from L1 to L3 and then decreased up to L5 level in both sexes. The difference between male and female vertebrae was not significant at any level. Present study showed statistically significant difference in the height of lumbar pedicle of male and female lumbar vertebrae (right side L1 to L4 and on left side at all vertebral levels). Thickness of lumbar pedicle (L1 to L3 on right side and L1, L2, L3 and L5 on left side). However, statistically significant difference was not observed in the length of pedicle. Thus height and thickness of pedicle showed sexual dimorphic features particularly at L1 to L3 levels, which can be considered for determination of sex in skeletal remains.

Table 6: Length $(\mathrm{mm})$ of left side pedicle in male and female vertebrae.

\begin{tabular}{|c|c|c|c|c|c|c|}
\hline Vertebra & Sex & Mean & S.D. & Range & p Value & Significance \\
\hline \multirow{2}{*}{ L1 } & $M$ & 6.54 & 0.73 & $5-8$ & \multirow{2}{*}{0.724} & \multirow{2}{*}{ NS } \\
\hline & $\mathrm{F}$ & 6.61 & 0.93 & $5-8$ & & \\
\hline \multirow{2}{*}{ L2 } & $M$ & 7.08 & 0.89 & $5-10$ & \multirow{2}{*}{0.663} & \multirow{2}{*}{ NS } \\
\hline & $\mathrm{F}$ & 6.97 & 1.1 & $6-9$ & & \\
\hline \multirow{2}{*}{ L3 } & $M$ & 7.85 & 1.36 & 5-11 & \multirow{2}{*}{0.816} & \multirow{2}{*}{ NS } \\
\hline & $\mathrm{F}$ & 7.93 & 1.34 & $6-12$ & & \\
\hline \multirow{2}{*}{ L4 } & $M$ & 6.13 & 0.81 & $4-8$ & \multirow{2}{*}{0.783} & \multirow{2}{*}{ NS } \\
\hline & $\mathrm{F}$ & 6.19 & 0.81 & $5-8$ & & \\
\hline \multirow{2}{*}{ L5 } & $M$ & 5.44 & 1 & $4-7$ & \multirow{2}{*}{0.271} & \multirow{2}{*}{ NS } \\
\hline & $\mathrm{F}$ & 5.67 & 0.75 & $4-8$ & & \\
\hline
\end{tabular}

\section{DISCUSSION}

The transpedicular screw fixation of lumbar spine is developed as a very successful method of spinal fixation which is needed for various spinal problems like fracture in lumbar spine, resection of tumours in vertebral bodies, gross spondylolisthesis and lumbar instabilities [6]. Vertebral pedicles are used very often for procedures performed inside the vertebral body like biopsies, vertebroplasties or kyphoplasties $[8,9]$.

In pedicle screw insertion, the screw is passed through posterior aspect of pedicle into the body of vertebra anteriorly. By using the screws, several devices such as rods, plates or wires can be applied to the spine for immobilization or fixation. The success of technique depends upon ability of the screw to obtain and maintain purchase within the vertebral body. This is based on accuracy of choice of screw, size of pedicle and the quality of bone of the pedicle. Larger diameter screws are stronger and gave better results; hence majority of surgeons prefers as large size of screw as possible for any given pedicle. Inappropriate size of (oversized) screw may result in cortex perforation of pedicle or fracture of pedicle and can result in dural tears, leakage of cerebrospinal fluid and injuries to nerve roots [5]. Hence the knowledge of height, thickness and length of pedicle helps for deciding 
the size of pedicle screw.

Table 7: Comparison of height of pedicle between previous and present study.

\begin{tabular}{|c|c|c|c|c|c|c|c|c|}
\hline Authors & $\mathrm{N}$ & Side & Sex & L1 & L2 & L3 & L4 & $\llcorner 5$ \\
\hline \multirow{2}{*}{$\begin{array}{l}\text { Singel TC (2004) Saurashtra Region } \\
\text { [6] }\end{array}$} & 45 & - & M & 14.7 & 15 & 14.7 & 14 & 13.4 \\
\hline & 15 & & $\mathrm{~F}$ & 15.5 & 14.5 & 14.8 & 14 & 13.25 \\
\hline Aruna N (2011) South Indian [10] & 44 & & M & 7.39 & 7.87 & 9.88 & 11.42 & 12.33 \\
\hline Singh J (2013) North Indian[11] & 20 & - & M & 14.6 & 14.3 & 14.4 & 13.4 & 14.4 \\
\hline \multirow{2}{*}{ Wankhede H (2014) [12] } & \multirow{2}{*}{23} & R & - & 13.9 & 14 & 14.6 & 14.1 & 12.8 \\
\hline & & L & - & 13.8 & 13.8 & 14.7 & \begin{tabular}{|l|l}
14.1 \\
\end{tabular} & 12.5 \\
\hline \multirow{4}{*}{$\begin{array}{c}\text { Present study } \\
\text { (Maharashtra region) }\end{array}$} & \multirow{4}{*}{70} & \multirow{2}{*}{ R } & M & 13.98 & 14.4 & 15.23 & 13.11 & 11 \\
\hline & & & $\mathrm{F}$ & 13.07 & 13.72 & 14.26 & 12.16 & 10.59 \\
\hline & & \multirow{2}{*}{ L } & M & 13.8 & 14.15 & 14.85 & 12.78 & 10.89 \\
\hline & & & $\mathrm{F}$ & 12.91 & 13.39 & 14.11 & 12.02 & 10.19 \\
\hline
\end{tabular}

Singel TC et al [6] has reported that height of pedicle increased from L1 to $L 2$ and decreased from $L 3$ to $L 5$ level in both sexes. Aruna $\mathrm{N}$ et al [10] reported that height of pedicle gradually increased from L1 to L5 level. Singh J et al [11] observed that the mean height of pedicle decreased from L1 to L4 level and increased at L5 level. Wankhede $\mathrm{H}$ et al [12] in the study reported that the height of pedicle goes on increasing from L1 to L3 levels and decreased at $L 4$ to $L 5$ level. The findings of present study are similar to findings observed by Wankhede $\mathrm{H}$ et al [12]. Thus the patterns of increase or decrease in the height of pedicle are different in different studies and varied according to population.

The mean values of height of present study were comparable with Singel TC et al [6] at L3 level. In male vertebrae, they were comparable with study by Singh J et al [11] at L2 and L3 levels.

Table 8: Comparison of thickness of pedicle between previous and present study.

\begin{tabular}{|c|c|c|c|c|c|c|c|c|}
\hline Authors & $\mathrm{N}$ & Side & Sex & L1 & L2 & L3 & L4 & L5 \\
\hline \multirow{2}{*}{$\begin{array}{c}\text { Singel TC 2004 } \\
\text { (Saurashtra region) [6] }\end{array}$} & 45 & - & M & 8.2 & 8.5 & 10.4 & 13.5 & 18.2 \\
\hline & 15 & - & $\mathrm{F}$ & 8.5 & 8.75 & 10.6 & 13.8 & 19.25 \\
\hline $\begin{array}{c}\text { Aruna N } 2011 \\
\text { (South Indian) [10] }\end{array}$ & 44 & - & M & 14.82 & 14.4 & 14.15 & 13.85 & 17.52 \\
\hline $\begin{array}{l}\text { Jaskaran Singh } 2013 \\
\text { (North Indian) [11] }\end{array}$ & - & - & M & 14.6 & 14.3 & 14.4 & 13.4 & 14.4 \\
\hline \multirow{2}{*}{ Wankhede H (2014) [12] } & 23 & $\mathrm{R}$ & - & 6.8 & 8.6 & 8.6 & 10.5 & 14.5 \\
\hline & 23 & L & - & 6.6 & 8.4 & 8.6 & 10.5 & 14.6 \\
\hline \multirow{4}{*}{$\begin{array}{c}\text { Present Study } \\
\text { (Maharashtra Region) }\end{array}$} & 50 & \multirow{2}{*}{ R } & M & 7.47 & 8.33 & 9.51 & 10.44 & 13.65 \\
\hline & 50 & & $\mathrm{~F}$ & 6.4 & 7.19 & 8.51 & 10.02 & 12.58 \\
\hline & 50 & \multirow[b]{2}{*}{ L } & M & 7.51 & 8 & 9.41 & \begin{tabular}{|l|}
10.74 \\
\end{tabular} & 13.98 \\
\hline & 50 & & $\mathrm{~F}$ & 6.63 & 7.39 & 8.46 & 10.21 & 12.83 \\
\hline
\end{tabular}

The thickness of pedicle in present study increased gradually from L1 to L5 levels in both sexes. This finding of the present study was similar to study by Singel et al [6] and study by Wankhede $\mathrm{H}$ et al [12], whereas in study by Aruna [10], thickness decreased from L1 to L4 and abruptly increased at $L 5$ level. The mean values of present study at $L 2$ level in male were comparable with Singel et al and at L1, L2, L3 and L4 levels with study by Wankhede et al.

Table 9: Comparison of length of pedicle between previous and present study.

\begin{tabular}{|c|c|c|c|c|c|c|c|c|}
\hline Authors & $\mathrm{N}$ & Side & Sex & L1 & L2 & L3 & L4 & L5 \\
\hline $\begin{array}{c}\text { Sing J } \\
\text { (North Indians)[8] }\end{array}$ & 20 & - & $M$ & 9.4 & 9.2 & 9.5 & 9 & 8.6 \\
\hline \multirow{4}{*}{$\begin{array}{c}\text { Present Study } \\
\text { Maharashtra Region }\end{array}$} & 50 & $\mathrm{R}$ & \multirow{2}{*}{$\mathrm{M}$} & 6.74 & 7.17 & 7.91 & 6.24 & 5.49 \\
\hline & 50 & $\mathrm{~L}$ & & 6.54 & 7.08 & 7.85 & 6.13 & 5.44 \\
\hline & 50 & $\mathrm{R}$ & \multirow{2}{*}{$\mathrm{F}$} & 6.84 & 7.39 & 8.07 & 6.28 & 5.68 \\
\hline & 50 & $\bar{L}$ & & 6.61 & 6.97 & 7.93 & 6.19 & 5.67 \\
\hline
\end{tabular}

Singh J et al [8] reported the length of pedicle decreased at L2 and increased at L3 and again decreased at L4 to L5 vertebrae in males. In present study length of pedicle increased from $L 1$ to $L 3$ and decreased at $L 4$ to $L 5$ vertebrae in male and female. In present study the mean values of length of pedicle was lower than study by Jaskaran Singh et al.

\section{CONCLUSION}

There are no mean values of the vertebral dimensions that are valid for all populations. The ethnical and racial differences are bound to present for population of different geographical areas. This necessitates the study of particular geographic area and population to find out the definitive range of normal values for that particular population

Thus the morphometric study of above mentioned parameters of lumbar pedicles can be useful in designing pedicle screw and in preoperative planning. This study will also be helpful for anthropometric studies as well as for forensic investigations.

\section{ACKNOWLEDGEMENTS}

The authors are thankful to the Institute and all the departments of Anatomy of Maharashtra region.

\section{ABBREVIATIONS}

S.D. - Standard deviations S. - Significant

M - Male N.S. - Not Significant

$\mathbf{F}$ - Female $\mathbf{N}$ - Sample size $\mathbf{R}$ - Right side

H.S. - Highly Significant L - Left side 


\section{Conflicts of Interests: None}

\section{REFERENCES}

[1]. Standring S. Back: Gray's Anatomy, The anatomical Basis of Clinical Practice, $40^{\text {th }}$ edition, Spain, Churchill Livingstone. 2008: 712-714,716-717,723724, 730-731.

[2]. Pal GP, Routal RV. Transmission of weight through lower Thoracic and lumbar regions of the vertebral column in man.J.Anat.1987; 152:93-105.

[3]. Chawla K, Sharma M, Abhaya A. Kochhar S. Morphometry of the lumbar pedicle in West India. Eur. J .Anat. 2011; 15(3):155- 161.

[4]. Vinay KV, Beena DN, Vishal K. Lumbar pedicle morphometry in South Indians using CR-35X digitizer. Indian Journal of Fundamental and Applied Life Sciences 2012; 2(2):173-178.

[5]. Amonoo -Kuofi HS. Age related variations in the horizontal and vertical diameters of the pedicles of Lumbar spine. Journal of Anatomy.1995; 186: 321328.

[6]. Singel TC, Patel MM, Gohil DV. A study of width and height of lumbar pedicles in Saurashtra region. Anat .Soc. India. 2004; 53(1): 4-9.

[7]. Prakash, Latha V, Prabhu, Rajanigandha et al. Morphometry of vertebral pedicles: a comprehensive anatomical study in the region. Int. J.Morphol. 2007; 25(2):393 - 406.
[8]. Defino HLA, Vendrame JRB. Morphometric study of Lumbar vertebrae's Pedicle. Acta OrtopBras.2007; 15 (4): 183-186.

[9]. Ramachandran K, Ganesan D. Morphometric study of pedicles of lumbar vertebrae and its clinical significance. International Journal of Medical and Applied Sciences.2015;4(1): 189-193.

[10]. Aruna N, Rajeshwari TM. A study of Lumbar Pedicle size in South Indians. Anatomica Karnataka.2011; 5 (2): 69-73.

[11]. Singh J, Pahuja K, Khatri J. Morphometric analysis of the lumbar vertebrae in North Indian Population. Asian Journal of Pharmaceutical and Health Sciences. 2013; 3 (4): 830-834.

[12]. Wankhede HA, Jadhav SS, Katti AS, Herekar NG, Morphometric study of the pedicle of the dried adult human lumbar vertebrae. International Journal of Anatomy Physiology and Biochemistry.2014; 1(1):15.

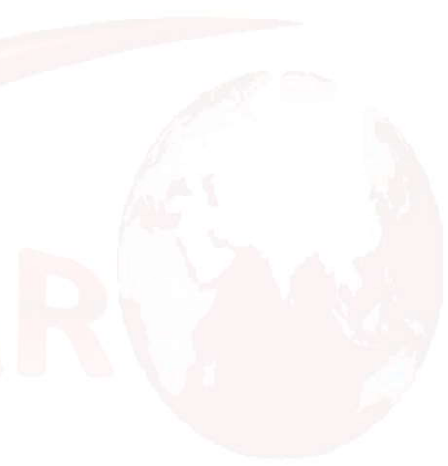

How to cite this article:

Yallawa S Kamble, Pramod R. Kulkarni, Uttama U Joshi. MORPHOMETRY AND SEXUAL DIMORPHISM OF LUMBAR PEDICLES IN DRY BONES OF MAHARASHTRA REGION. Int J Anat Res 2017;5(4.3):4654-4659. DOI: 10.16965/ijar.2017.428 